http://dx.doi.org/10.4314/bajopas.v12i1.58S

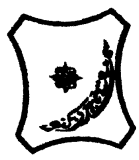

Bayero Journal of Pure and Applied Sciences, 12(1): 386 - 394

ISSN $2006-6996$

\title{
COMPARATIVE STUDY OF SUCROSE PLASTICISED BIOPLASTIC DERIVATIVES WITH SELECTED PETRO-PLASTICS
}

\author{
Agwamba, E. C., ${ }^{1,2}$ Hassan, L.G., ${ }^{2}$ Sokoto, A.M. ${ }^{2}$ and Achor, M. ${ }^{3}$ \\ 1. Department of Chemical Sciences, Faculty of Sciences, Clifford University, Owerrinta, Abia \\ State.
}

2. Department of Pure and Applied Chemistry, Faculty of Science, Usmanu Danfodiyo University Sokoto, Sokoto.

3. Department of Pharmaceutics, Faculty of Pharmaceutical Science, Usmanu Danfodiyo University Sokoto, Sokoto.

Corresponding author: agwamba.ernest@gmail.com, agwambae@clifforduni.edu.ng

ABSTRACT

The major setback with most bioplastics is their inherent inability to compete with Petroplastics in terms of high production cost, and there poor mechanical properties like low tensile strength and percentage extension. This study explore the availability and affordability of mango starch as raw material for bioplastic production and compared some of its mechanical properties with High density Polyethylene (HDPE), Low density polyethylene (LDPE), polyvinyl chloride (PVC), and Polyurethane (PU). Mango starch was used to synthesize bioplastic derivatives, with variable levels of sucrose as plasticiser, aqueous $\mathrm{HCl}$ concentration and Carboxymethyl cellulose (CMC) as additive and the mechanical properties of the derived biofilms was measured and compared with the selected Petro-plastics films. It was observed that B1 thermoplastic derivatives have the higher young modulus of $5.658 \mathrm{GPa}$ than that obtained for PVC (4.682 GPa), and PU (3.771 GPa) but show no significant difference and significantly higher than that of HDPE (0.049 GPa), and LDPE (0.063 GPa) ( $P<0.05)$. B2 and B3 indicated a young modulus that is significantly lower than PU and PVC, but showed a young modulus that is higher than LDPE and HDPE with no significant difference $(p<0.05)$. The FTIR spectra indicate that hydrogen bond was formed in the bulk matrix of the bioplastic derivatives at a band region of $3600-600 \mathrm{~cm}^{-1}$ wavenumber with broad discrete peaks.

Keywords: Petro-plastics; Bioplastics; Mechanical Properties; Plasticization; Mango starch

\section{INTRODUCTION}

The question that is most asked is "why do we prefer Petro-plastic over bioplastic, even with all the advantages", the reason is not farfetched from the limitation usually associated with its processability derived from their mechanical properties, and physicochemical properties in which water and gas barrier are the major factors. This has resulted in a sudden surge of investigations into bioplastics to improve these properties and make them more versatile, robust, and desirable in a competitive polymer market especially in single-use polymer applications. Since they are non-biodegradable and non-compostable, Petro-plastics has resulted to problem of environmental pollution both inland and marine, has resulted to decimation of marine life as a result of ingestion and entanglement (UNEP, 2015) and with the recent alarming investigation by Orb Media in 2017 reveal the presence of microplastics i.e.
Petro-plastic fragments in drinking water around the world, that pose a great concern for public health (Kosuth et al., 2018; Medrano et al., 2019), so the environmental unfriendliness is no more in question. Varda et al., (2014), asked in his research titled "Can a starch-based Plastic be an option of Environmental Friendly Plastic" as against other bioplastics like PHA, PLA, PHB, and PCL, PEG and Petro-plastic, and the factor of production cost comes to play. Although starch is not the only renewable raw material from which bioplastic can be made, as protein-based bioplastic has also shown excellent properties when applied in an injection mould (Felix et al., 2016). But starch is still the most affordable, and readily available raw biopolymer that can be easily converted into bioplastic by acidic hydrolysis and non-volatile plasticizer which are also very affordable, also available Varda et al., (2014). 


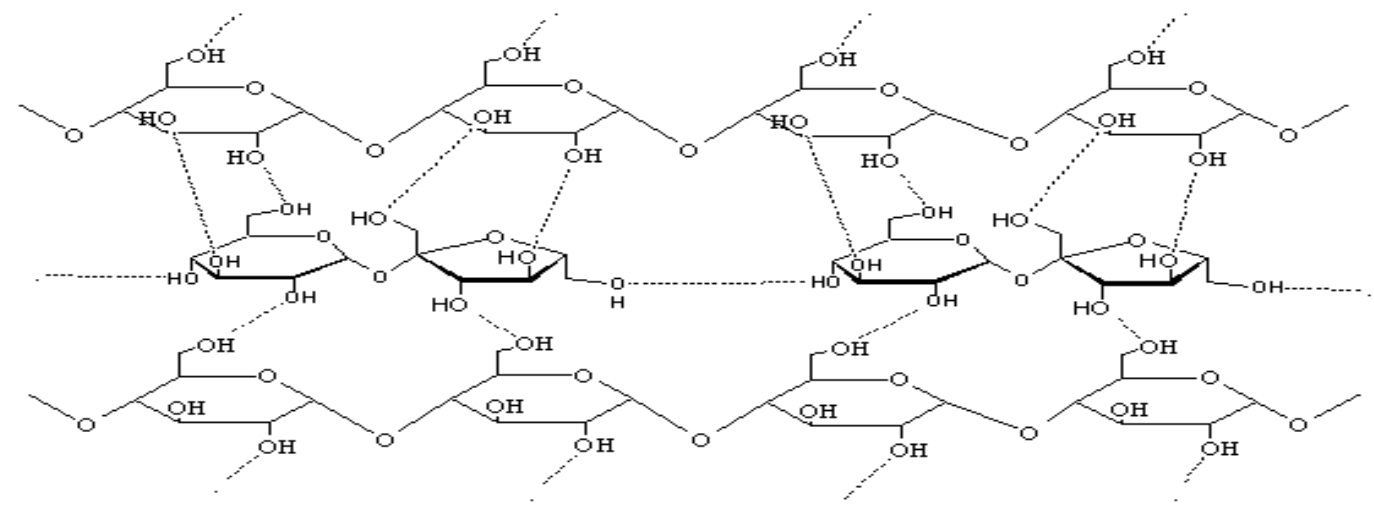

Scheme 1: Proposed Hydrogen Bond interaction between the Matrix of Starch and
sucrose (SUC)

The process involves in the preparation of polyhroxylalkanoate PHA from microorganism is very tedious and costly in time and resources when compared to thermoplastic starch. Amongst all the biobased-biodegradable bioplastics, thermoplastic starch represents a single most feasible alternative to replace Petroplastic since its properties can be tailored to specific with the help of additives such as plasticizer and flexibility. Most of the bioplastic found today in the market are made from starch, and represent about $85-90 \%$ of bioplastics in the global market (Bastioli, 2000). The most widely investigated and used polyol in thermoplastic starch production is probably glycerol, and this may be due to its high safety profile in food and biomedical applications, inexpensive, and non-volatile nature (Mekonnen et al., 2013). Mechanical properties and water barrier are two properties of polymer that influence the choice and end application of these materials both domestically and industrially. The use of Ammonium salt and urea as a plasticizer in thermoplastic starch has showed improved mechanical property than HDPE and produced a very transparent bioplastic under hot compression mould which is also recyclable (Abbot et al,2012). The drive to switch to sustainable plastic from the conventional is not yet a global practice, like the most countries, especially sub-Saharan African is yet to key into the potential of renewable material as a source of raw a materials for bioplastic production may be due to its dependence on the food source for starch needed for bioplastic production. But starch derived from mango seed kernel is a promising alternative for raw biomaterial for application in bioplastic production, as the seed are discarded after consumption and treated as Agricultural waste though compostable still added to the pollution problem. and will not required additional cultivation of mango plant on scarce land, since it exists in abundance in most countries in the world (Fowomola, 2010), and (Kittiphoon, 2012), since other plant sources such as corn, cassava, may require the land expanse of land could result in possible deforestation (Abbot et al, 2012). Therefore, this study will involve the use of starch extracted from waste Mango seed kernel, plasticized with Sucrose and reinforced with CMC in order to synthesize thermoplastic starch comparable with Petro-plastic in mechanical property. The stress, strain, percentage extension, and young modulus will be measured and compared for significant differences with the selected Petroplastic films of PU, PVC, LDPE, and HDPE.

\section{MATERIALS AND METHODS}

Mango starch powder and chemicals used was obtained from laboratory faculty of pharmaceutical science of Usmanu Danfodiyo University Sokoto and was used in this study without further modification or purification.

\section{a. Preparation of bioplastic derivative} films

With some modification, the method described by Wissinger et al., 2016 was adopted. To a 50 $\mathrm{cm}^{3}$ beaker, $13.00 \mathrm{~cm}^{3}$ of distilled water was added; follow by $1.25 \mathrm{~g}$ starch power, $2.0 \mathrm{~cm}^{3}$ of $\mathrm{HCl}$ was added, followed by sucrose, and carboxymethyl cellulose (CMC) as shown in table 1 below. The mixture was placed on a magnetic stirrer, and heated and stirred slowly on a hot plate until it gets to $70^{\circ} \mathrm{C}$. The mixture started out white in colour and change to transparent or translucent and thickens. Once the initial white colour of the starch has completely changed and the mixture had thickened, $2.0 \mathrm{~cm}^{3}$ of $\mathrm{NaOH}_{(\mathrm{aq})}$ was added to neutralized the acid (same concentration with $\mathrm{HCl}_{(\mathrm{aq})}$ acid ) and removed from the heat. The hot mixture was slowly cast into a labelled Petri-dish and was dried in the oven for 12 hours at $70{ }^{\circ} \mathrm{C}$. 
Table 1: The Composition of Sucrose Plasticised Bioplastic Derivatives (sample)

\begin{tabular}{lcccc}
\hline $\begin{array}{l}\text { Sample } \\
\text { code }\end{array}$ & $\begin{array}{c}\text { Plasticizer } \\
\text { Type }\end{array}$ & $\begin{array}{c}\text { Plasticizer } \\
(\%)\end{array}$ & CMC (\%) & $\begin{array}{l}\text { HCl } \\
(\mathbf{M})\end{array}$ \\
\hline B1 & SUC & 180 & 30 & 0.1 \\
B2 & SUC & 80 & 70 & 0.1 \\
B3 & SUC & 80 & 30 & 0.1 \\
\hline
\end{tabular}

B: bioplastic derived from sucrose, SUC = sucrose, CMC: carboxymethyl cellulose

\section{b. Mechanical Determination \\ i. Tensile Strength (Stress)}

The mechanical properties were ascertained using a locally fabricated testing machine, according to the ASTM D882-09 standard method. A dumbbell-shaped template was made from flat iron bar to cut the test bioplastic derivatives into a dumbbell shape to length, thickness, width measured using a Vernier calliper and micrometer screw gauge respectively; the bioplastic specimen was examined to find the area free of defects such as small tears, ridges, air bubbles, curves, etc. A portion of the sample was cut out using the template.

The sample was carefully placed, secured and fastened at both ends of the dumbbell on the clamp of the tensile strength measuring machine. At one end of the movable clamp, a string was attached, and the other end of the string, a plastic container was attached. Gradually water was added to the container in very small quantity until the sample breaks around the middle, and the weight of the water added plus container was recorded as the weight that broke the sample, also the elongation at the point of breaking was recorded.

The cross-sectional area in square meters was calculated by converting the thickness and width from millimeters to meters. Tensile Strength (Stress) was calculated using the equation (i):

Tensile Strength (Stress) $=\frac{\text { Force }(N)}{\text { Area }\left(m^{2}\right)}$ (i)

Convert tensile strength from $\mathrm{Pa}$ to GPa. Where $1 \mathrm{GPa}=1 \times 10^{-9} \mathrm{~Pa}$

\section{ii. Elongation at Break and Strain}

The elongation at break $(\varepsilon)$ is the maximum elongation that the specimen can reach when pulled, before failure. It is measured as the ratio between the original length of the specimen and length at the moment of break. It expresses the capability of a material to resist changes of shape without crack formation.

The strain is the maximum extension the bioplastic can stretch under tension, while, Elongation at break is an indication of bioplastics flexibility and is expressed as a percentage. Percentage Elongation at break was calculated as follows using equation (ii), and (iii):

$$
\begin{aligned}
& \text { Strain }=\frac{\text { Extension }(m)}{\text { Initial Length }(m)} \\
& \% \text { Elongation at break }(\varepsilon)=\frac{\text { Extension }}{\text { Initial Length }} \times 100 \text {-- }
\end{aligned}
$$

\section{iii. Young Modulus}

This is the ratio of stress to strain, and this property defines the ultimate application of polymer. This property was calculated using the equation (iv) shown below;

Young Modulus $=\frac{\operatorname{Stress}(G P a))}{\operatorname{Strain}}$

\section{c. Determination of Hydrogen-Bond formation with Fourier Transformed Infrared Spectroscopy (FT-IR) analysis}

The sample was dried and IR spectra recorded with an Agilent-FTIR spectrometer, at $27^{\circ} \mathrm{C}$ from 650 to $4000 \mathrm{~cm}^{-1}$ range, background scanned at 64 , sample scanned at 32 , and the resolution was 4, and fitted with a compatible PC running recommended operating system as described by Maulida et al., (2016)

\section{d. Statistical Analysis}

The outcome of the experiment was analyzed for the significant difference using analysis of variance (ANOVA). The multiple comparisons were performed by Fisher LSD method with 95\% confidence interval using Minitab(R) statistical software (version 17). The statistical significant difference was declared at $p<0.05$. 
Special Conference Edition, November, 2019 RESULTS AND DISCUSSION

The result from Figure 1 and Table 1 shows that B1 has a significantly high Young Modulus for thermoplastic starch, compared with that of PU, PVC, LDPE, HDPE, all measured under the same condition. B1 indicates a young modulus that is significantly higher than B2 and B3, while B2 has a higher young modulus than B3 but are not significantly different $(p<0.05)$. It was observed that B1 thermoplastic derivatives have the higher young modulus of $5.658 \mathrm{GPa}$ than that obtained for PVC (4.682 GPa), and PU (3.771 GPa) but show no significant difference and significantly higher than that of HDPE (0.049 GPa), and LDPE (0.063 GPa) ( $p<0.05)$. $B 2$ and B3 indicated a young modulus that is significantly lower than PU and PVC, but showed a young modulus that is higher than LDPE and HDPE with no significant difference ( $p<0.05$ ). This implies that the bioplastic B1 is stiff, strong, and possess mechanical strength that share similarities with the PVC and PU and could be used in similar applications with some medication perhaps in physical properties. B2 and B3 are suitable for similar application like packaging materials as HDPE and LDPE since they show even higher young modulus. The higher strength of sucrose plasticized bioplastics (B1 and B2) could be attributed to the chemical structure and composition of sucrose. Sucrose is polyols, disaccharides, these multiple hydroxyl groups present contributes immensely in the intermolecular cross-linking with the starch biopolymer chain, thereby improving the overall strength of the bioplastics. Hydrogen bonding plays a vital role in the overall strength of the bioplastic, as a gives a more composite biopolymer, and this strength improves as the numbers of hydroxyl group increases, and this observation in higher young modulus, is a result of higher adhesion due to similarity in the matrix and fiber polarities of the reactants been carbohydrate all through i.e. starch, sucrose, and CMC as suggested by Van de-Velde and Piekens (2002). Ultimately the young modulus as observed increased with higher amount of sucrose.

Table 2: The result for Mechanical Property of Bioplastic derivatives and the Standard Petro-plastics

\begin{tabular}{|c|c|c|c|c|c|c|c|c|}
\hline \multirow{2}{*}{ Sample } & \multicolumn{2}{|c|}{ Stress (mpa) } & \multicolumn{2}{|c|}{ Strain $(\mathbf{c m})$} & \multicolumn{2}{|c|}{$\begin{array}{c}\text { Young modulus } \\
(\mathrm{GPa})\end{array}$} & \multicolumn{2}{|c|}{$\begin{array}{c}\text { Elongation } \\
(\%)\end{array}$} \\
\hline & Mean & SD & Mean & SD & Mean & SD & Mean & SD \\
\hline B1 & 934.215 & 63.314 & 0.166 & 0.012 & 5.658 & 0.796 & 17.302 & 0.419 \\
\hline B2 & 447.002 & 51.147 & 0.330 & 0.055 & 1.397 & 0.372 & 32.95 & 5.490 \\
\hline B3 & 271.654 & 64.444 & 0.708 & 0.141 & 0.384 & 0.055 & 70.80 & 2.410 \\
\hline PU & 363.778 & 120.952 & 0.106 & 0.040 & 3.771 & 1.655 & 10.556 & 0.429 \\
\hline PVC & 257.949 & 99.273 & 0.059 & 0.016 & 4.682 & 2.482 & 5.897 & 1.554 \\
\hline LDPE & 146.123 & 31.274 & 2.908 & 1.963 & 0.063 & 0.003 & 290.754 & 1.441 \\
\hline HDPE & 44.426 & 8.453 & 0.933 & 0.288 & 0.049 & 0.006 & 93.302 & 1.057 \\
\hline
\end{tabular}

KEY: PU = Polyurethane, PVC = Polyvinylchloride, LDPE = low density polyethylene, HDPE = High density polyethylene.

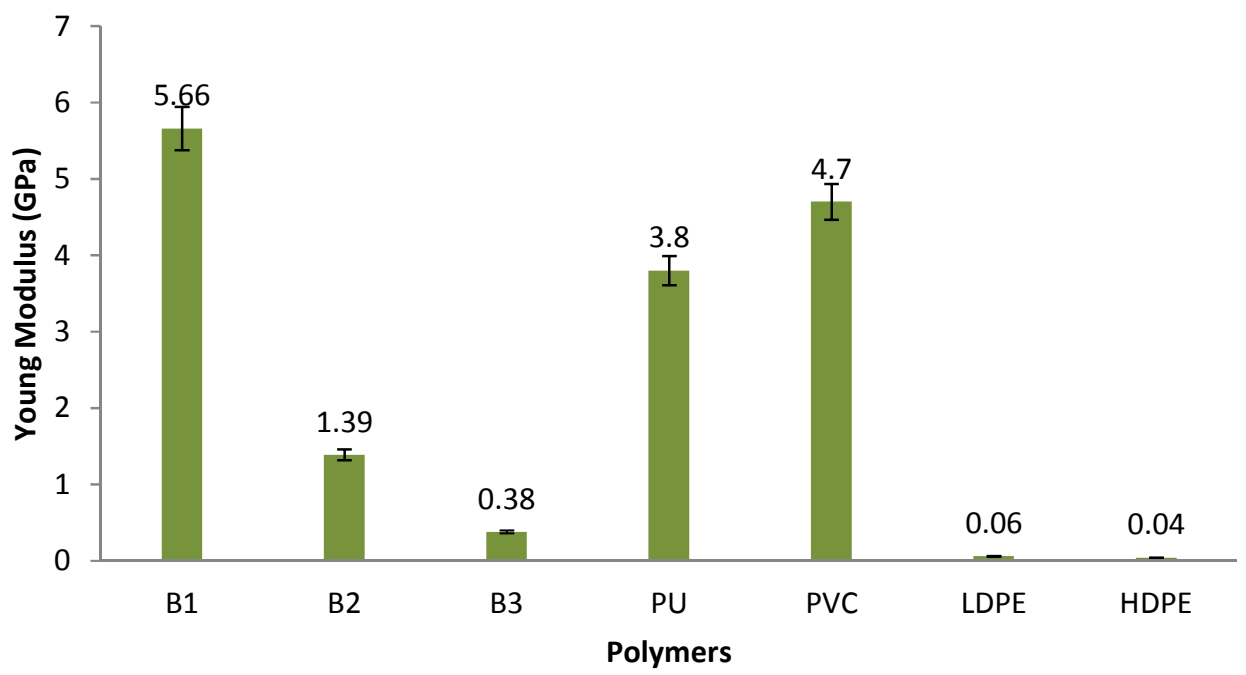

Figure 1: Compares Young modulus of Bioplastic derivatives and Standard Petro-plastics 
Special Conference Edition, November, 2019

Compared to bioplastic filled with nanofiller Zinc Oxide as reinforcement produced a material with diminishing young modulus with glycerol as plasticizer (Harunsyah et al., 2017) which is inconsistent with this investigation when CMC and sucrose as plasticiser. The results obtained by Eterigho et al., 2017, show that blending with PVA at $80 \%$ produces bioplastic with young modulus of $000.31 \mathrm{GPa}$, while this study obtained young modulus of $0.5199 \mathrm{GPa}$ at $0 \%$, $0.4863 \mathrm{GPa}$ at $30 \%, 1.3971 \mathrm{GPa}$ at $70 \% \mathrm{CMC}$, this goes to show that CMC it is a better reinforcement material when compared to PVA and $\mathrm{ZnO}$ nanofillers, this can be attributed to a high degree of Hydrogen bond and intermolecular interaction within the matrix biocomposite. According to Khurmi and Sedha (2012), the range of obtainable young modulus for Petro-plastics (HDPE, LDPE, PU, or PVC e.t.c.) is between 0.07 to $4.00 \mathrm{GPa}$, which is in agreement with the bioplastic derivatives, and the standard Petro-plastic film obtained for this studies for sample B1 that show a young modulus of $5.66 \mathrm{GPa}$ that is significantly higher than $4.68 \mathrm{GPa}$ of PVC film observed for this study and agrees with values stated by Khurmi and Sdha (2012).

Figure 2 and Table 1, shows the percentage elongation of the sucrose plasticised thermoplastic mango starch compared with petro-polymers which includes PU, PVC, LDPE, and HDPE. The results show that the percentage elongation of the bioplastic derivatives increases significantly when sucrose (80 to $180 \%$ ) 17.30 $\%$ in $\mathrm{B} 1$ to $70.80 \%$ in B3 and CMC (70 to $30 \%$ ) in B2 and B3 was significantly decreased from 32.96 to $70.80 \%(p<0.05)$. but varies from the petro-polymer PU and PVC has significant difference in the percentage elongation of 10.56 and $5.89 \%$, are significantly different from
LDPE and HDPE. LDPE showed the highest percentage elongation of $290.8 \%$, and PVC is lowest at $5.9 \%(p<0.05)$. It was observed that has the highest derived percentage elongation is $70.80 \%$ for B3 which has is significant difference from all other bioplastics derivatives $(p<0.05)$. Sucrose derived bioplastics behave more like composite and show little elongation and only breaks at high tensile stress and have lower percentage elongation, but higher young modulus i.e. displaying an inverse relationship. From Table 3, shows the FTIR spectra corresponding to bioplastic derivatives, and starch. The bioplastic derivative spectra corresponding to the band of starch, CMC and sucrose i.e., bands at 920 and $1148 \mathrm{~cm}^{-}$ ${ }^{1}$ (Mendes et al., 2016). it was observed that the presence of $\mathrm{H}$-bonding network has resulted to more broaden and discrete low-frequency peaks as seen the region of $3600-3000 \mathrm{~cm}^{-1}$ wavenumber in spectra obtained for all the bioplastic derivatives, compared to hydrogen bond observed in the starch spectrum to have less discrete peak and a shift of the stretching frequency in the region of $3500-3070 \mathrm{~cm}^{-1}$. Starch biopolymer spectrum show in a region of 970 and $1200 \mathrm{~cm}^{-1}$ and this was observed in all derivatives of bioplastics. The presence of carboxylate (-COO-) in the CMC gives the strong bands at about 1646.30, 1422.55 and $1360 \mathrm{~cm}^{-1}$ which is line with absorption band obtained by Jiang et al., (2011) but is almost absent in starch. The symmetrical stretching vibration for - $\mathrm{CH} 2$ - was observed with an intense peak at $2929.97 \mathrm{~cm}^{-1}$ in all the variety of bioplastic derivatives also observed in the unplasticized starch but at less broaden peaks but is similar to 2914 observed by Mendes et al., (2016).

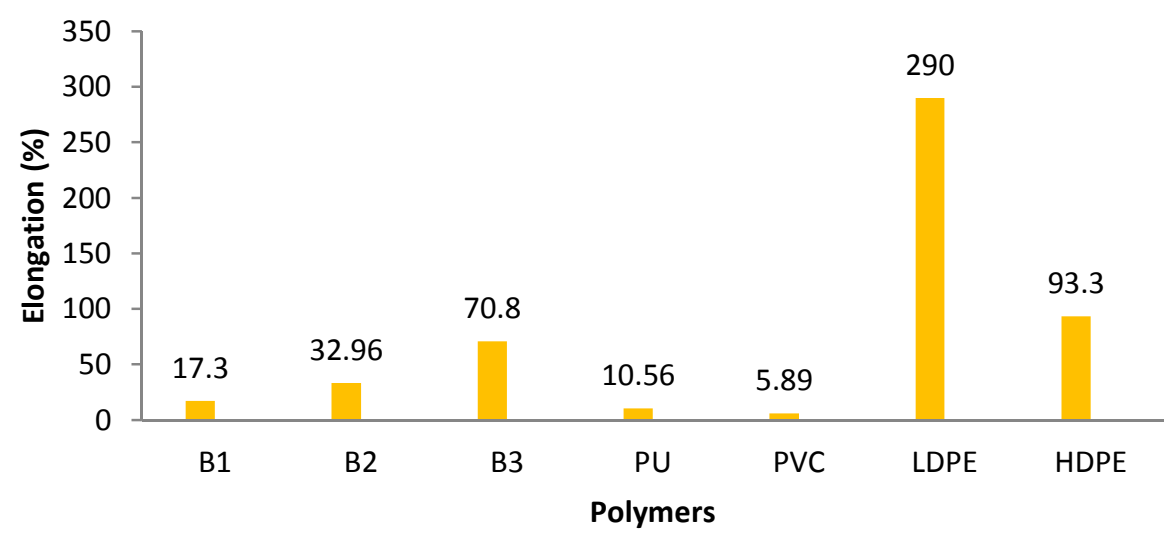

Figure 2: Compares Percentage Elongation of Bioplastic derivatives and Standard Petroplastics 
Special Conference Edition, November, 2019

Result of FTIR Analysis for Sucrose Plasticised Bioplastic derivatives.

Table 3: FTIR Spectra of Pristine Mango Starch, and sucrose plasticised bioplastic

derivatives

Functional Group $\quad$ Wave number $\left(\mathrm{cm}^{-1}\right)$

\begin{tabular}{lcccc} 
& Mango & B1 & B2 & B3 \\
O - H & 3260.84 & 3336.85 & 3340.58 & 3342.62 \\
C - H & 2937.84 & 2925.64 & 2931.60 & 2984.17 \\
C = O & 1646.77 & 1650.34 & 1649.55 & 1668.46 \\
C-O & 1041.12 & 1037.16 & 1028.98 & 1075.49 \\
\hline
\end{tabular}

\section{CONCLUSION}

Result has shown that thermoplastic starch with higher comparable mechanical properties to PVC, and PU, HDPE, and LDPE could be derived from Mango starch plasticised with sucrose and reinforced with $\mathrm{CMC}$. The derived sucrose plasticised bioplastics have an edge of better the rate of biodegradation in case it is used as a single-use-plastic compared to petro-plastic which are the major contributors to environmental pollution which have negatively affected land and marine ecosystems (UNEP, 2015). Therefore, it can be concluded that

\section{REFERENCES}

Abbott, A.P., Ballantyne, A.D., and Conde, J.P. (2012) Salt Modified Starch: Sustainable, Recyclable Plastics. Green Chemistry. 14: $1302-1307$.

Bastioli, C. (2000). Global Status of The Production Of Biobased Packaging Materials Conference Proceedings. The food Biopack conference, Denmark, Copenhagen. 200: 2-7

Eerkes-Medrano D., Leslie, H.A., and Quinn, B. (2019). Microplastics in Drinking Water: A Review and Assessment. Current Opinion in Environmental Science \& Health 2019, 7: 69-75

Eterigho, E.J., Farrow, T. S., Ejejigbe S.E., and Gideon O. D. (2017). Study of the Physical Properties and Biodegradability of Potato-Starch Based Plastics. Proceedings of the World Congress on Engineering and Computer Science. 2.(online publication).

Felix, M., and Perez-Puyana, V., Romero, A., and Guerrero, A.. (2016). Production and Characterization of Bioplastics Obtained by Injection Moulding of Various Protein Systems. Journal Polymer Environment. 1-10. sucrose plasticized bioplastics could be applied in the production of biodegradable bioplastics cups, spoon, planting bags plate and other single-use that requires high tensile materials, these bioplastics derivatives could be applied in production of packaging bag, mulching bag and other single-use purposes with some modification. Therefore, mango starch could be utilized to synthesize bioplastic derivatives that are affordable, available, with suitable mechanical properties that are significantly comparable with some Petro-plastics.

Fowomola, M.A. (2010). Some Nutrients and Antinutrients Content Of Mango (Mangifera indica) Seed. African Journal of Food Science, 4(8): 472-476.

Harunsyah, M. Y. and Reza, F. (2017). Mechanical Properties of Bioplastics Cassava Starch Film with Zinc Oxide Nanofiller as Reinforcement. IOP Conf. Series: Materials Science and Engineering, 210: 012-015

Jiang, Q., Gao, W., Li, X., and Liu, Z. (2011). Synthesis and Properties Of Carboxymethyl Pueraria Thomsonii Benth. Starch. Starch/Sta" rke. 63: 692699.

Khurmi R.S. and Sedha R.S. (2012). Materials Science. S. Chand and Company Ltd. Code: 10A 109

Kosuth M, Mason SA, Wattenberg EV: Anthropogenic Contamination of Tap Water, Beer, and Sea Salt. PLOS ONE 2018, 13:e0194970.

Lawal, O. S., Lechner, M. D., and Kulicke, W. M. (2008). Single and Multistep Carboxymethylation Of Water Yam (Dioscorea Alata) Starch: Synthesis and Characterization. International Journal Biopolymer Macromolecules, 42: 429435. 
Special Conference Edition, November, 2019

Li, X., Gao, W., Huang, L., and Wang, Y. (2010). Preparation and Physicochemical Properties Of Carboxymethyl Fritillaria ussuriensis Maxim Starches. Carbohydrate. Polymer, 80: 768-773.

Mehta V., Marjadi D. and Dharaiya N. (2014). Can a Starch-Based Plastic be an Option of Environmental Friendly Plastic?. Journal of Global Biosciences, 3(3): 681685

Mekonnen, T., Mussone P., Khalil $\mathrm{H}_{\text {., }}$ and Bressler D. (2013). Progress in BioBased Plastics and Plasticizing Modifications. Journal of Materials Chemistry A. 1: 13379-13389

Mendes, J.F., Paschoalin, R.T., Carmona, V.B., Neto, A. R.S., Marques, A.C.P., Marconcini, J.M., Mattoso, L.H.C., Medeiro, E.S., and Oliveira, J.E. (2016). Biodegradable Polymer Blends Based On
Corn Starch and Thermoplastic Chitosan Processed By Extrusion. Carbohydrate Polymers, 137: 452-458

UNEP (2015). Biodegradable Plastics and Marine Litter. Misconceptions, Concerns and Impacts on Marine Environments. United Nations Environment Programme (UNEP).

Van de Velde and Kiekens P. (2002). Biopolymers: Overview of Several Properties and Consequences on their Applications. Polymer Testing 2: 433442

Wissinger, J., Harris, R., Johnson, A., Ahrenstorff, C., and Seifert, L. (2016). Make it and Break it: Bioplastic from Plant Starch. University of Minnesota Centre for Sustainable Polymers. A NSF Centre for Chemical Innovation: 1-9.

\section{Appendix}

Table 4: Basic Statistical Analysis for Young Modulus of Sucrose plasticised Bioplastics and selected petroplastics

\begin{tabular}{lccccccc}
\hline Runs & B1 & B2 & B3 & PU & PVC & LDPE & HDPE \\
\hline 1 & 5.6240 & 1.4161 & 0.3278 & 4.0258 & 3.9412 & 0.0640 & 0.0428 \\
2 & 4.8791 & 1.0155 & 0.4372 & 5.2840 & 7.4501 & 0.0592 & 0.0547 \\
3 & 6.4700 & 1.7596 & 0.3862 & 2.0036 & 2.6557 & 0.0657 & 0.0491 \\
Mean & 5.6577 & 1.3971 & 0.3837 & 3.7711 & 4.6823 & 0.0630 & 0.0488 \\
(GPa) & & & & & & & \\
SD & 0.7960 & 0.3724 & 0.0547 & 1.6550 & 2.4816 & 0.0033 & 0.0060 \\
SE & 0.6336 & 0.1387 & 0.0030 & 2.7390 & 6.1585 & 0.0000 & 0.0000 \\
\hline
\end{tabular}

SD: Standard deviation, SE: Standard error

Table 5: One Analysis of Variance for Young Modulus using the Fisher LSD Method and 95\% Confidence

\begin{tabular}{lccccc}
\hline Factor & $\mathbf{N}$ & Mean (GPa) & SD & $\mathbf{9 5 \%}$ CI & Grouping \\
B1 & 3 & 5.658 & 0.796 & $(4.202,7.113)$ & A \\
B2 & 3 & 1.397 & 0.372 & $(-0.059,2.853)$ & B \\
B3 & 3 & 0.3837 & 0.0547 & $(-1.0719,1.8394)$ & B \\
PU & 3 & 3.771 & 1.655 & $(2.316,5.227)$ & A \\
PVC & 3 & 4.68 & 2.48 & $(3.23,6.14)$ & A \\
LDPE & 3 & 0.06297 & 0.00337 & $(-1.39266,1.51859)$ & B \\
HDPE & 3 & 0.04887 & 0.00595 & $(-1.40676,1.50449)$ & B
\end{tabular}

$\mathrm{N}$ : Experimental run, SD: Standard Deviation, CI: Confidence Interval.

Pooled SD $=1.17551$. Means that do not share a letter are significantly different. 
Special Conference Edition, November, 2019
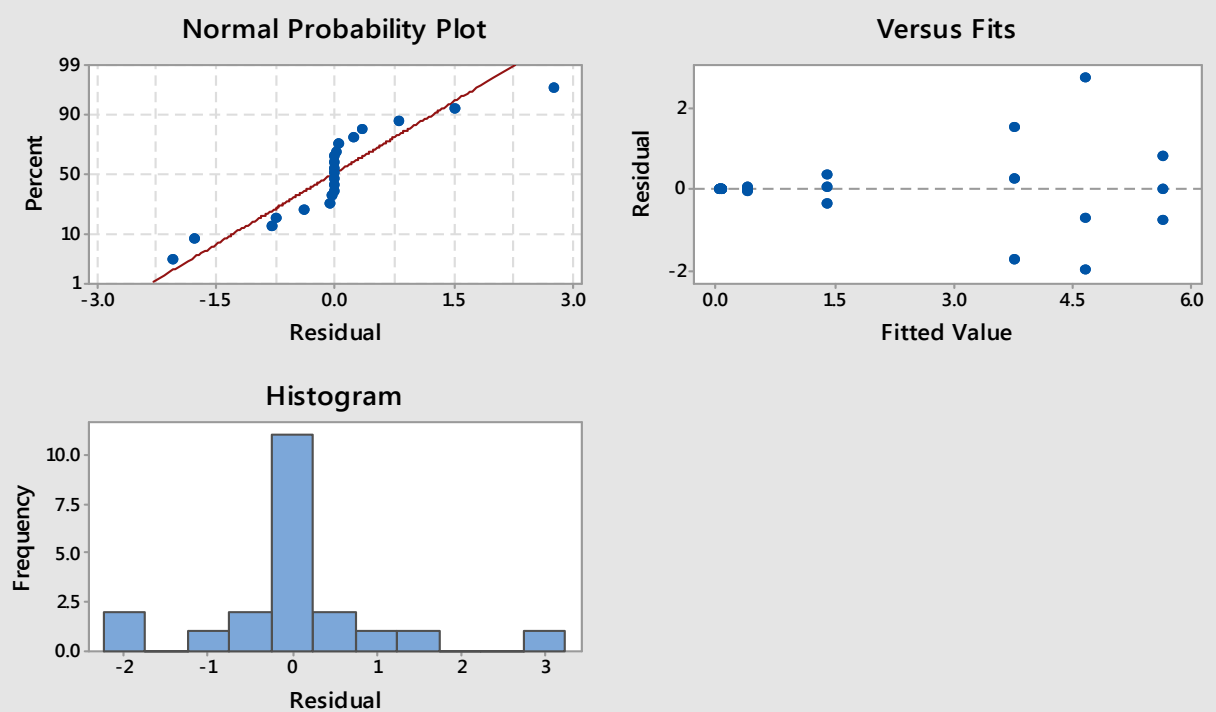

Figure3: Residual Plots for Young Modulus of Sucrose plasticised Bioplastics and Selected Petroplastics

Table 6: Basic Statistical Analysis for Percentage Elongation of Sucrose plasticised Bioplastics and selected Petro-plastics

\begin{tabular}{lccccccc}
\hline Runs & B1 & B2 & B3 & PU & PVC & LDPE & HDPE \\
\hline $\mathbf{1}$ & 16.8831 & 31.5068 & 72.2047 & 10.1429 & 5.0000 & 291.8292 & 94.3770 \\
$\mathbf{2}$ & 17.7215 & 39.0244 & 68.0253 & 10.5238 & 5.0000 & 291.3158 & 93.2650 \\
$\mathbf{3}$ & 17.3023 & 28.3333 & 72.1832 & 11.0000 & 7.6923 & 289.1167 & 92.2631 \\
Mean & 17.3023 & 32.9549 & 70.8044 & 10.5556 & 5.8974 & 290.7539 & 93.3017 \\
$\mathbf{( \% )}$ & & & & & & & \\
SD & 0.4192 & 5.4906 & 2.4068 & 0.4295 & 1.5544 & 1.4409 & 1.0575 \\
SE & 0.1757 & 30.1472 & 5.7926 & 0.1844 & 2.4162 & 2.0762 & 1.1182 \\
\hline
\end{tabular}

SD: Standard deviation, SE: Standard error

Table 7: One Analysis of Variance for Percentage Elongation using the Fisher LSD Method and 95\% Confidence

\begin{tabular}{lccccc}
\hline Factor & N & Mean (\%) & SD & 95\% CI & Grouping \\
B1 & 3 & 17.302 & 0.419 & $(14.272,20.332)$ & A \\
B2 & 3 & 32.95 & 5.49 & $(29.92,35.98)$ & B \\
B3 & 3 & 70.80 & 2.41 & $(67.77,73.83)$ & C \\
PU & 3 & 10.556 & 0.429 & $(7.526,13.586)$ & D \\
PVC & 3 & 5.897 & 1.554 & $(2.867,8.927)$ & E \\
LDPE & 3 & 290.754 & 1.441 & $(287.724,293.784)$ & F \\
HDPE & 3 & 93.302 & 1.057 & $(90.272,96.332)$ & G \\
\hline
\end{tabular}

$\mathrm{N}$ : Experimental run, SD: Standard Deviation, CI: Confidence Interval.

Pooled SD $=2.44688$. Means that do not share a letter are significantly different. 
Special Conference Edition, November, 2019
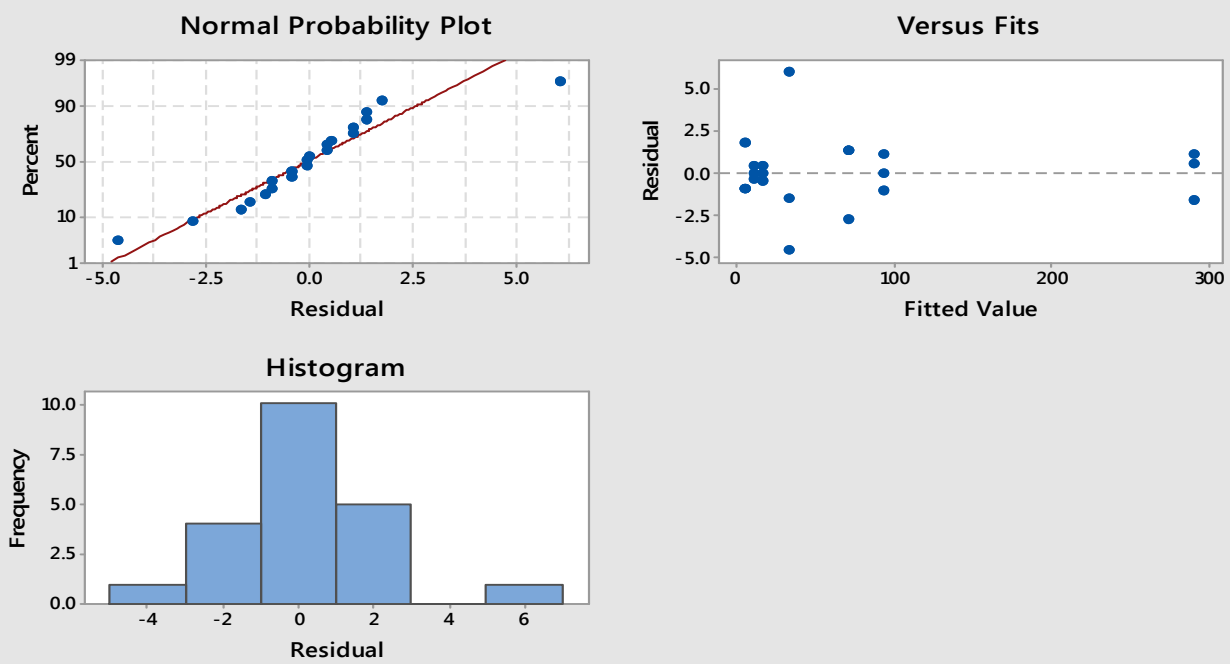

Figure 4: Residual Plots for Young Modulus of Sucrose plasticised Bioplastics and Selected Petroplastics

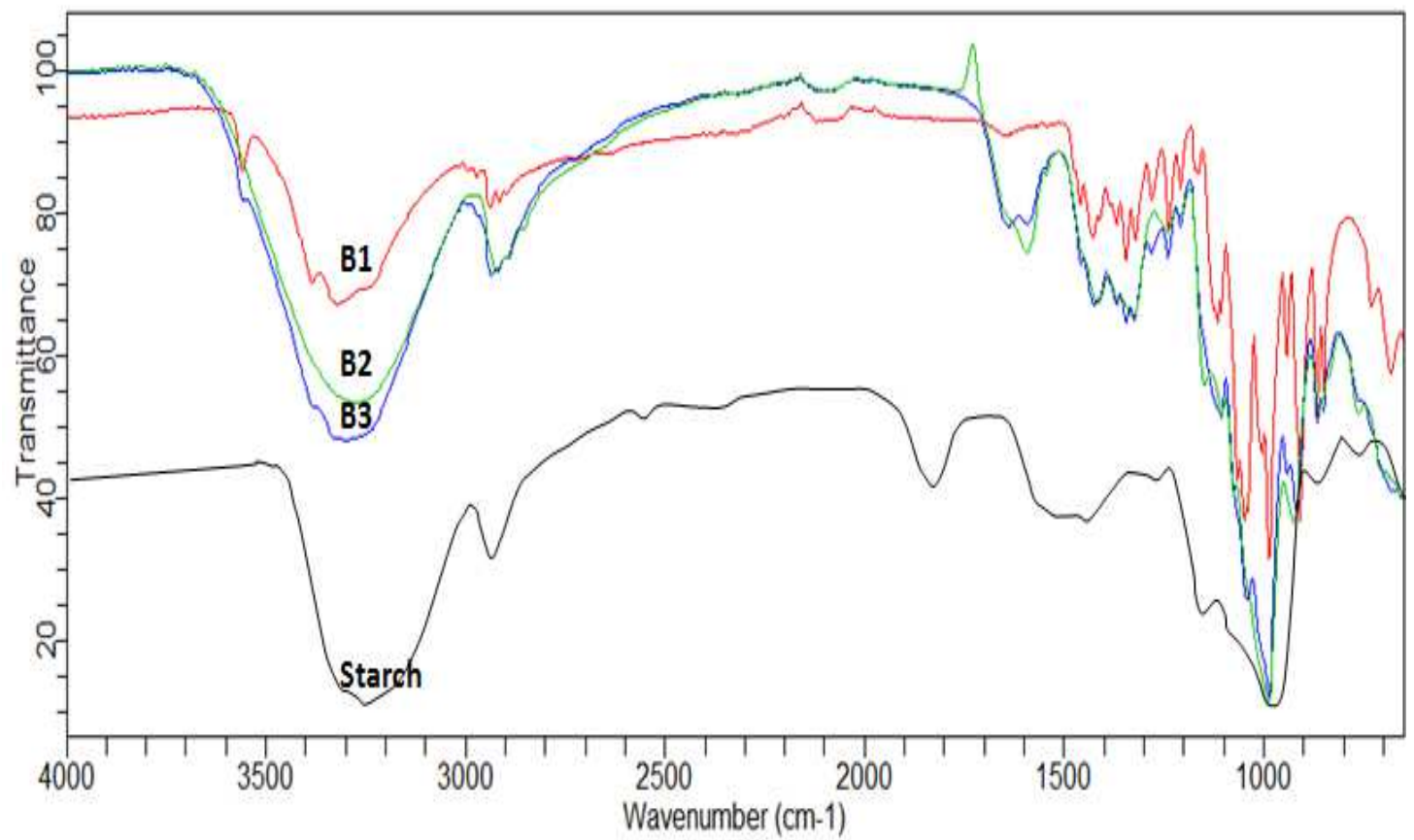

Figure 5: FTIR spectra for sucrose Plasticised Bioplastics (B1, B2, and B3) and Pristine Mango Starch 